\title{
A Petrobrás e a exploração de Petróleo Offshore no Brasil:um approach evolucionário
}

\author{
José Benedito Ortiz Neto*, Armando João Dalla Costa ${ }^{\dagger}$
}

Sumário: 1. Introdução; 2. Inovações Tecnológicas, apropriação pelas firmas e desenvolvimento econômico: aspectos teóricos; 3. Da disponibilidade de petróleo em alto mar para as inovações tecnológicas da Petrobras; 4. Considerações finais sob o respaldo teórico.

Palavras-chave: Petróleo; Teoria Evolucionária; Inovações Tecnológicas; Petrobras; Offshore. Códigos JEL: L16; L22; L53.

Inovações tecnológicas têm refletido positivamente para o crescimento e desenvolvimento econômico em todo o globo. Estudos apontam para as vantagens da ação conjunta de firmas e/ou instituições em busca de tais inovações, em detrimento das atividades isoladas. Neste trabalho, serão analisados os aspectos inovadores ocorridos dentro da exploração de petróleo realizada pela Petrobrás em águas profundas, segmento conhecido como Offshore. Como sustentação teórica dos fatores analisados, o referencial será principalmente proveniente da teoria evolucionária do crescimento econômico. Através de um exercício de relação entre prática e teoria, o objetivo do trabalho será demonstrar o sucesso da empresa, por atuar de maneira muito semelhante ao que seriam as premissas teóricas referidas anteriormente. Para chegar a tais conclusões, o trabalho será dividido em três partes. A primeira apresenta as variáveis teóricas que condicionarão a estruturação da parte posterior, que será a descrição das inovações realizadas em quase 20 anos de P\&D na exploração de petróleo offshore. A última parte é um misto entre conclusões e uma relação das atividades exercidas pela companhia brasileira frente aos preceitos teóricos.

Technological Innovation had been changed into economic growth and development in all world. Many settled studies had highlighted the advantages of

*Economista pela Universidade Estadual de Londrina. Mestrando em Desenvolvimento Econômico no PPGDE da UFPR. Bolsista da CAPES. E-mail: neto@londrina. net.

$\dagger$ Doutor em História Econômica pela Université de Paris III (Sorbonne Nouvelle). Professor no Departamento de Economia e no PPGDE; coordenador do NUPEM - Núcleo de Pesquisa em Economia Empresarial da UFPR. Homepage: http://www . empresas . ufpr.br. E-mail: ajdcosta@ufpr.br. 
collective research programs against the option to carry out the same programs lonely. At this paper, will be sketch the innovators aspects built up by Petrobras to develop a broader and new efficient technology process to explore oil in depth water, summoned by Oil Offshore Technology. The theoretical sustentation riddled here provide from Evolutionary Economic Growth Theory. Through an exercise of knit practice and theory, the main goal is to show the success attained, by the institution, to use similar theoretic premises pointed out latter. To reap this conclusion, the outline of the paper is as follows. The first describe the theoretical features wherein hold up the follow section, the description of innovations through 20 years of RED in offshore oil exploration. The last one, will be a mix flanked by conclusions and the link between Petrobras offshore activities and theoretical principles.

\section{INTRODUÇÃO}

O interesse econômico pelo petróleo teve início no começo do século XIX, ao ser utilizado como fonte de energia, substituindo o gás proveniente da destilação do carvão vegetal, para a iluminação pública, o chamado "petróleo iluminante". Esta função perdurou apenas até as décadas de 1870/80, quando Thomas Edison conseguiu sistematizar e desenvolver o conhecimento em energia elétrica, suplantando qualquer outra fonte de iluminação. Com isto, o interesse comercial pelo fóssil reduziu drasticamente, voltando apenas no final do século XIX, principalmente no século XX, a partir da invenção dos motores a gasolina e a diesel. Desde então, o insumo passou a ter justificativas comerciais para ser explorado ad infinitun, ou até seu esgotamento (Debeir, 1993).

Este novo emprego do petróleo fez surgir, além de uma das mais ricas indústrias do planeta, uma nova e importante metodologia de crescimento, o uso da ciência nas atividades fabris. A indústria do petróleo, conjuntamente com a indústria química, serão as pioneiras a utilizar a ciência, através de programas de $\mathrm{P} \& \mathrm{D}$, como instrumento de crescimento econômico ${ }^{1}$. A partir de então, o emprego de P\&D nas mais diversas indústrias, tem sido uma ocorrência bastante ostensiva, devido sua essencialidade no desenvolvimento dos novos produtos e processos tecnológicos das organizações. Muitos autores irão ressaltar a essencialidade desta temática como fizeram Freeman e Soete (1997) ao conceber os programas de P\&D tecnológico, como o elemento central de uma estratégia, que permite e facilita 0 avanço da instituição até uma posição de liderança do mercado.

O país que liderou o processo de aprendizagem científica na indústria do petróleo foi os EUA (Freeman e Soete, 1997). Muitos dos fundamentos científicos globais necessários para o uso e exploração do petróleo, decorreram dos esforços dos cientistas atuantes neste país. Entretanto, nem todo este avanço foi suficiente para viabilizar a produção de petróleo no Brasil. Isto porque, o Brasil iria descobrir anos mais tarde, no final da década de 1960, que a maior parte das reservas petrolíferas estaria localizada no mar, e não em terra, como acontecia nos demais países, como os EUA. Em função desta realidade, os EUA desenvolveram uma trajetória tecnológica, acerca da extração do mineral, quase que totalmente para bacias territoriais, a chamada tecnologia onshore ou in land. E o pouco do conhecimento tecnológico de exploração de petróleo em alto mar da época, também não condizia com a realidade brasileira, visto que a profundidade média dos poços brasileiros era bastante superior à dos norte-americanos.

Diante de tal impasse tecnológico, as autoridades brasileiras tiveram de decidir entre produzir uma tecnologia condizente com a realidade local; adquirir tal tecnologia via contrato com instituições in-

\footnotetext{
${ }^{1} \mathrm{~A}$ indústria química germânica foi a primeira a utilizar esta temática para o desenvolvimento da tinta sintética nas décadas de 1860/70, mas encontrou na ascensão do petróleo, que demandava por descobrimentos químicos, como o catalisador e métodos mais eficientes de refino, uma grande fonte de incentivos para avançar no uso da ciência (Freeman e Soete, 1997).
} 
ternacionais; ou então importar o mineral. Talvez influenciados pela consciência nacionalista militar, frente a importância estratégica dos recursos naturais do país, bem como pela ausência de Know How internacional, a decisão foi produzir localmente um sistema de inovações que permitisse a exploração do petróleo em alto mar, tecnologia conhecida como offshore. Seja qual foi a motivação desta decisão, a Petrobras por intermédio de seu Programa de Capacitação Tecnológica em Águas Profundas - PROCAP - criado em 1986, tem trilhado um caminho de inúmeras descobertas, que proporcionou à instituição, o título de líder internacional em tecnologia de exploração de petróleo em águas profundas.

Para compreender as forças intrínsecas, e até ocultas, da expansão tecnológica dentro de um processo de inovações, o presente trabalho adotou o referencial teórico neo-schumpeteriano, em especial os chamados evolucionários, para apresentar o desenvolvimento da tecnologia offshore, realizada pela Petrobras. Esta opção teórica consiste no fato destes autores analisarem essencialmente o comportamento das variáveis que envolvem o progresso técnico, com destaque aos sistemas de inovação em função das instituições e pela concepção das externalidades geradas pela tecnologia no período ex post da competição, o que na concepção deste trabalho, conseguirá refletir o desempenho da empresa brasileira de petróleo.

Neste contexto, a primeira seção do trabalho visa esclarecer os tópicos teóricos relevantes ao estudo. A segunda seção, por sua vez, destaca as particularidades inovativas da produção offshore. Por último, serão descritos alguns aspectos conclusivos, que permitam uma referência mais explícita entre as atividades da Petrobras com os preceitos teóricos.

\section{INOVAÇÕES TECNOLÓGICAS, APROPRIAÇÃO PELAS FIRMAS E DESENVOLVIMENTO ECONÔMICO: ASPECTOS TEÓRICOS}

Até os anos 1960, boa parte dos estudos acerca de tecnologia eram puramente técnicos, todavia, economistas sempre reconheceram a importância das inovações para a expansão da produtividade, conseqüentemente para a performance competitiva dos países. Um dos primeiros nomes dentro da ciência econômica a analisar este tema com maior profundidade foi Joseph Schumpeter. Este chegou a colocar a tecnologia numa posição central da teoria do crescimento e desenvolvimento econômico.

Com o passar dos anos a intensidade dos estudos em tecnologia foi ampliado. Os anos 1980 foram marcados pelo maior interesse no conhecimento tecnológico aplicado ao setor industrial, e este por ser o mais dinâmico dentro da economia, acabou sendo, segundo alguns autores (Bell et alii, 1984), um dos principais elementos causadores da divergência nas taxas de crescimento entre países desenvolvidos e em desenvolvimento. De acordo com tais princípios, quando avanços tecnológicos são empreendidos por países ainda em desenvolvimento, numa magnitude que permita estabelecer vantagens competitivas, haverá uma tendência de convergência para com os países já desenvolvidos. Podendo ser dito que tais inovações mostram-se como atalhos rumo a patamares mais elevados de renda e de desenvolvimento.

Na concepção de Bell et alii (1984), são dois os fatores principais que proporcionam a possibilidade inovativa: a capacidade tecnológica e a capacidade produtiva de um país/região.

Capacidade Tecnológica: são os recursos necessários para gerar e administrar as mudanças científicotecnológicas, como: habilidade, conhecimento, Know How dos agentes, e a estrutura institucional. A constituição do conhecimento científico do capital humano, por sua vez, será dado pelo aprendizado formal e tácito. O primeiro acontece dentro do espaço "escolar", já o segundo, será proveniente da experiência, da observação laborial, do próprio exercício de sua atividade. Valores que foram teorizados por Kenneth Arrow em 1962, através do conceito learning by doing, originalmente pelo texto da Review of Economic Studies (junho): “The economic implications of learning by doing” (citado por Rosenberg 1982, e posteriormente por Rosenberg (1982), com o princípio do learning by doing. Indiretamente, ambos os conceitos envolvem a capacidade de transformação do conhecimento para um objetivo diverso.

RBE Rio de Janeiro v. 61 n. 1/p. 95-109 Jan-Mar 2007 
Ao processo de formação de conhecimento, que conduzirá à inovação, deve estar atrelado o fato do conhecimento ser cumulativo, que terá basicamente duas implicações: i) a existência do gap tecnológico, pois países que estimulam a competência tecnológica há mais tempo, terão um "estoque" de conhecimento maior e, por conseguinte, situam-se numa posição mais provável de liderança; ii) a competência tecnológica dos países não tem como mudar de maneira tão intensa por um período de tempo muito prolongado, uma vez que não tem como avançar sem possuir estoque de conhecimento. Com isto cria-se uma dependência temporal às condicionantes inovativas de natureza tecnológica, assim $o$ que a firma pode esperar em fazer tecnologicamente no futuro, está fortemente restringida pelo que foi capaz de fazer no passado. (Dosi, 1982, p.225)

Será então, a capacidade tecnológica que proporcionará a maior difusão e absorção do conhecimento tecnológico, criando assim uma outra variável de estoque: a Capacidade Produtiva. Tem-se que a soma da capacidade tecnológica e produtiva, formarão as inovações, ou ao menos, a possibilidade técnica para tal.

Com a junção destas capacidades, dentro de um contexto de P\&D em tecnologia, tem-se entre outros, a formação dos Paradigmas Tecnológicos. Estes poderão ser definidos como modelo e exemplo de soluções de problemas tecnológicos selecionados, através de determinados princípios que derivam da ciência natural e material tecnológico escolhido. Sendo, portanto, o conjunto de pesquisas e resultados que fornecem procedimentos tecnológicos envoltos em conhecimento específico capazes de resolver e aperfeiçoar diversos problemas referentes à tecnologia e à técnicas produtivas, respectivamente. Por fim, é o próprio processo da pesquisa tecnológica e seu estabelecimento como modelo a ser seguido. 0 paradigma irá pré-determinar as tecnologias a serem adotadas e as evitadas, bem como procedimentos que devam ser utilizados, quais propriedades químicas devem ser desenvolvidas ou mantidas, quais são os trade-offs envolvidos na questão, entre outras particularidades.

O desenvolvimento, sofisticação e, até mesmo manutenção de um paradigma, será "conduzido" pelas trajetórias tecnológicas realizadas dentro deste. A trajetória tecnológica será a direção do progresso tecnológico dentro do paradigma, no qual será diretamente influenciado por variáveis tecnológicas e econômicas. Nas palavras de Dosi (1988, p.227): "Uma trajetória tecnológica é a atividade do progresso tecnológico entre o trade-off da economia e tecnologia definidos por um paradigma".

As escolhas, muitas vezes, serão definidas dentre diversos caminhos (trajetórias) possíveis, sendo que o estoque de conhecimento será o principal delimitador da fronteira do paradigma, e a aprendizagem deverá fomentar ou restringir o sentido das trajetórias, bem como detectar novas oportunidades de investimento que possam surgir "no caminho" da evolução tecnológica (efeito spill over). Pode-se compreender tal contextualização, como uma crítica ou complementação, ao referencial neoclássico a respeito de tecnologia, que possui uma visão menos dinâmica a respeito dos efeitos da tecnologia na economia.

Em relação ao comportamento das trajetórias, ou dos caminhos escolhidos, estará inerentemente ligada ao perfil inovador; ao nível de risco aceito pelas empresas; e por fim, à incerteza intrínseca dos distintos resultados possíveis. Estes limitadores podem ser conceitualizados como fatores econômicos, sociais, institucionais e tecnológicos:

Fatores econômicos o interesse econômico das organizações, onde se destaca a lucratividade, condições mercadológicas e disponibilidade de gastos em P\&D;

Fatores Sociais e Institucionais o grau de necessidade do produto para a sociedade; aspectos ambientais; interesse político, no sentido de destinar recursos, como aconteceu nos programas militares e espaciais nos EUA, após a II guerra, que proporcionaram vultosas somas para aqueles que desenvolvessem P\&D em semi-condutores, além de garantirem a compra (Dosi, 1982); ou então nas diversas políticas de substituição de importações, que supostamente, através de políticas protecionistas, permitia-se que a indústria local criasse maiores condições de acúmulo de capital para depois então investir os recursos poupados. 
Fatores tecnológicos são constituídos basicamente pelo conhecimento, habilidade e Know-How tecnológico dos agentes envolvidos. O conjunto destes atributos irá determinar a exeqüibilidade de um projeto ou não, e principalmente, a capacidade tecnológica e a capacidade produtiva.

Na conjunção destes fatores, as decisões tecnológicas serão realizadas. Entretanto, referente ao exercício das escolhas, é necessário ater-se para o fato em potencial, de que as decisões tecnológicas em determinado momento, estarão condicionadas ao desenvolvimento do conhecimento passado, da mesma forma que projetarão algumas tendências futuras, ao que Rosenberg (1969) chamou de "imperativos tecnológicos" da pesquisa em tecnologia, pois esta, de certa forma, será temporalmente dependente. Podendo reconhecer este caminho de dependência ${ }^{2}$ como um fator limitador das competências da firma, será também um gerador de um ambiente em que as habilidades (skills) poderão ser mais produtivamente aplicadas, devido a rotina criada na especialização. Será desta trajetória dependente, que formará, juntamente com o marketing e a produção, o foco da empresa.

Será através do somatório da cumulatividade do conhecimento, da aprendizagem formal e tácita e da dependência de uma trajetória ao seu regime tecnológico, que em geral, os programas de P\&D formam a capacidade produtiva e tecnológica de uma instituição. E serão diversas as formas organizacionais, pelos quais são conduzidos tais programas. Ocorrem basicamente em Universidades, Governos e laboratórios privados. Em sua diversidade, as instituições irão concorrer e cooperar entre si de diversas maneiras, além de diferenciarem-se em tamanho, objetivo e mecanismos de atuação.

Aparentemente, os evolucionários em geral, mostram três possibilidades de desenvolvimento tecnológico, mas sempre inserido num contexto institucional: uma é o de P\&D isolado, outra de adquirir tecnologia de outra organização, e por último, o desenvolvimento de tecnologia de maneira integrada. Geralmente, a primeira opção será mais utilizada para pequenos aperfeiçoamentos tecnológicos, e não para o desenvolvimento de novas tecnologias propriamente ditas. A segunda opção tem suas vantagens, mas os problemas também existem, como o de lock in, dos elevados custos e riscos de transferência tecnológica e por dificilmente chegar a uma posição de liderança. A terceira opção vem se destacando como uma forte opção dentro da pesquisa industrial, no qual um conjunto de empresas irão se aliar, tanto horizontal quanto verticalmente, em programas de pesquisa.

Em referência à integração vertical, a não observância de tal prática, pode ter um reflexo quase devastador na dinâmica tecnológica desta indústria ou setor. A priori, o primeiro autor a dar maior ênfase a esta causalidade, foi Frankel (1955), que ao estudar a economia inglesa em meados do século $\mathrm{XX}$, encontrou uma forte correlação entre a baixa integração em algumas indústrias, especificamente a do aço, ferro e têxtil, como conseqüência da pouco-intensa difusão de inovações tecnológicas. Isto gerou perda de competitividade frente aos similares alemães e japoneses, no qual, se observava maior integração. Segundo o autor, este fato permitiu um maior número de inovações e, portanto, uma maior competitividade mercadológica. Posteriormente, o estudo de Kindleberger, 1964 (citado por Teece 1988, corroborou para a sustentação destes princípios, através da comparação entre a hegemonia da General Motors na indústria automobilística, pós década de 1930, quando esta integrou-se com uma empresa de energia elétrica, enquanto seus competidores não o fizeram. A integração foi feita com a General Eletric, com a qual conseguiram desenvolver o primeiro automóvel a combustão a diesel com partida elétrica. Foi a partir desta iniciativa, que no futuro, as demais empresas automotivas inseriram os engenheiros elétricos em suas equipes de trabalho.

A integração no conhecimento, por tais contextualizações, será considerada por alguns como o modelo de infra-estrutura em pesquisa a ser explorado, uma vez que existem indícios de que a integração proporcionará aos integrantes, produtos mais sofisticados e de maneira mais rápida do que sem a união. Tal metodologia está em consonância com a expansão liberalizante do comércio internacional, que intensificou a competição mercadológica. Para a manutenção das companhias, estas terão de se adaptar em tempo real às mudanças estipuladas pelo mercado, ou liderar tais transformações, sempre num pro-

${ }^{2}$ Conceituado teoricamente por Path - Dependence. 
cesso de inovações. Esta nova realidade tornou o empreendimento de empresas buscarem, de maneira isolada, produzir todo o conhecimento relevante e ainda transformá-lo em produtos e processos tecnológicos inovativos, uma saga próxima do impraticável. Logo, a estratégia via alianças empresarias, em torno da pesquisa e desenvolvimento, tornou-se uma manobra em ascensão.

A este artifício, estão atreladas algumas dificuldades, como a difusão do conhecimento entre as aliadas, principalmente se uma delas não possuir uma capacidade tecnológica e produtiva aquém do necessário; nos contratos realizados acerca da transferência tecnológica, fica difícil estimar custos, período e outros pormenores. Para minimizar as dificuldades e ampliar os resultados da ciência, alguns autores como Teece e Armour (1977, citado por Teece 1988), destacam que as pesquisas fora ou dentro da empresa não podem ser consideradas como substitutas, ou concorrentes, pelo contrário, o êxito das empresas, está muitas vezes no sucesso em se regrar o quanto deve ser desenvolvido in house, e quanto deve ser obtido externamente.

Mas seja qual for a intensidade da integração da pesquisa em uma empresa, para que os empreendimentos surjam e sejam aproveitados, dependerá da habilidade técnica e produtiva, em desenvolver e comercializar produtos, que possam utilizar, ao menos em partes, os custos já existentes da empresa, tais como: logística, equipamentos, capital humano, entre outros. Ou seja, o conhecimento acumulado será a variável predominante em questões referentes às inovações e programas de P\&D.

Perante estas variáveis informativas, o objetivo do trabalho consiste em apresentar um produto dentro da indústria do petróleo, que através de um significativo avanço tecnológico propiciado pela Petrobras, no qual muitas vezes foi alcançado pela integração na pesquisa, estabeleceu um novo paradigma referente ao processo de exploração e produção de petróleo em águas profundas. E pela versatilidade tecnológica do programa, vem permitindo o desenvolvimento de várias trajetórias e novas oportunidades de negócios, e principalmente a sustentabilidade do país em relação ao consumo x oferta de petróleo.

\section{DA DISPONIBILIDADE DE PETRÓLEO EM ALTO MAR PARA AS INOVAÇÕES TECNOLÓ- GICAS DA PETROBRAS}

\subsection{Histórico de tecnologias referentes à produção offshore}

A indústria offshore mundial teve seu nascimento datado entre os anos 1930 e 1950 na Venezuela e Golfo do México, respectivamente. A partir de então, a exploração começou a se expandir para o Mar do Norte e formou o primeiro pull de empresas nesta segmentação, entre elas a Shell, Exxon, Texaco e AGIP (Furtado, 1996). No Brasil, já no final de 1950, devido às análises geográficas, havia o conhecimento de que o país possuía reservas de petróleo em profundidade marítima, ainda ser uma definição precisa dos locais. A confirmação ocorreu pela descoberta do primeiro poço offshore em 1968, no Campo de Guaricema (SE), e a primeira perfuração, também em 1968, na Bacia de Campos, no campo de Garoupa (RJ). O ano seguinte, também foi marcado por mais descobertas, com o Campo de São Mateus (ES), e posteriormente no campo de Ubarana (ES), ambos na bacia de Potiguar. A partir destas primeiras descobertas, a Petrobras deu início a uma série de outras. Entretanto, tais descobrimentos não surtiram maior efeito, pelo fato das tecnologias existentes não serem condizentes com a realidade brasileira (História, 2005).

Para a exploração marinha, de maneira geral, pode-se sintetizar todo o processo em três conjuntos tecnológicos distintos, que por sua vez, são os objetos de pesquisa das companhias offshore: as plataformas, o sistema de perfuração e o mecanismo de transmissão do petróleo da profundeza para a plataforma.

A tecnologia de construção de plataformas, desenvolveu um trajetória que possibilitasse a sustentação fixa, a partir de estruturas que chegam até o subsolo marinho.Talvez o tipo mais comum dentre as plataformas com sustentação fixa, seja a Tension Leg Platform (TLP), pela idéia que uma perna possibilite 
um equilíbrio seguro. Diante de sua característica, a estrutura se torna ineficiente para profundidades maiores, o que demandará um mecanismo flutuante. Esta eficiência pode ser comprovada diante da plataforma da Shell Oil, filial americana da Royal Dutch Shell, instalada em Bullwinkle no Golfo do México a uma profundidade de 411 metros, ser a plataforma fixa mais profunda do mundo. Sua instalação, ocorrida em 1988, mostrou-se uma proeza perante o conhecimento em engenharia da época (Furtado, 1996).

O equipamento que realiza a principal parte do processo de extração do petróleo, tem nome de "Árvore de Natal". Com as descobertas de poços mais volumosos, bem como pelo uso de plataformas menores, do tipo embarcação, tornou-se necessário ter o menor peso possível sob a plataforma, com isto surgiu o sistema de produção antecipado, onde muitos equipamentos, outrora sob a plataforma, passaram a posicionar-se dentro da água, este sistema é chamado no exterior de subsea. A árvore de natal é um destes equipamentos e passou a ser denominada de Árvore de Natal Molhada.

Como ressaltado anteriormente, a tecnologia de perfuração é outra problemática a ser resolvida para a viabilização na produção de petróleo em alto mar. Esta tecnologia divide-se em duas etapas: 0 sistema de procura do petróleo (sondas) e a perfuração propriamente dita. O desafio inicial consistiu na construção de sondas marítimas móveis, no intuito de permitir um maior potencial e menor custo de eficiência na deteç̧ão de poços de petróleo.

As primeiras sondas foram instaladas sobre barcaças no Golfo do México no final dos anos 1930. Já na década de 1940, para uma customização e otimização maior, a trajetória tecnológica orientou-se para o desenvolvimento de sondas não mais instaladas, e sim adaptadas para esta função móvel. Assim sendo, estas se tornaram verdadeiras embarcações, que foram chamadas de "barco sonda" (sistema utilizado atualmente). Nos anos 1950, além dos barcos, foram realizadas sondas semi-submersíveis, que se instalavam nas plataformas. A década posterior, as trajetórias marcantes foram em relação à tecnologia de perfuração, que já no início conseguiu escavar grandes profundidades (Furtado, 1996).

Várias outras tecnologias complementares foram desenvolvidas paralelamente para possibilitar a produção offshore: as mais importantes eram as de colocação de dutos de escoamento da produção e de sísmica em meio marítimo.

Esse conjunto de tecnologias permitiu a expansão contínua da produção offshore, inclusive para o Mar do Norte que, a partir da década de 1970, passou a rivalizar com o Golfo do México em ordem de importância para o volume de investimentos. Todavia, no início da década de 1980 ficou cada vez mais claro que embora existisse tecnologia sísmica e de perfuração para atuar em águas profundas, o mesmo não ocorria com a de produção. O sistema tecnológico de produção, apoiado em plataformas fixas, constituído no Golfo do México deveria ser radicalmente reformulado para alcançar profundidades maiores.

Para que o Brasil pudesse entrar nesta segmentação da indústria do petróleo, por ter uma profundidade média de seus poços superior aos 1.000 metros, a necessidade de desenvolver novas tecnologias era a única opção. Depois de tomada a decisão, a Petrobras iniciou uma trajetória tecnológica original, através da proposta do sistema de produção flutuante. Diante da ausência do conhecimento científico necessário para tal empreitada, o país teve de suprir tal espaço na experiência internacional, onde mesmo que de maneira ainda embrionária, já existia um Know How em tecnologia offshore.

Como se observa, antes de tornar-se uma produtora de tecnologia offshore, a companhia teve de utilizar tecnologia importada, que era adaptada às condições locais de produção, através de um processo de inovações incrementais. Assim, antes de iniciar os vultosos programas em desenvolvimento tecnológico, mostrou-se condizente com o princípio de primeiro buscar o conhecimento através da aquisição externa com aperfeiçoamentos.

Deste esforço a empresa conseguiu obter seu primeiro hardware, uma sonda submersível. Depois disto, a firma propiciou uma aliança com os estaleiros navais nacionais, para conseguir, já em meados dos anos 1980, o primeiro hardware genuinamente brasileiro em tecnologia offshore ,que foi a reconversão das sondas, para pequenas plataformas de produção. Tais atitudes mostraram, que já no início, a 
empresa optou por parcerias em suas atividades de P\&D. Estratégia esta que a Petrobras saberá explorar em seus seqüentes programas de pesquisa.

\subsection{A evolução dos programas de pesquisa em tecnologia offshore no Brasil pós 1986}

Para melhor desenvolver as tecnologias de exploração de petróleo em grandes profundidades, e poder livrar-se da "limitação" externa, a Petrobras criou um programa de investimento em P\&D, isolado das demais atividades do grupo. Este programa ficou conhecido como PROCAP - Programa de Capacitação Tecnológica em Águas Profundas - que devido à perspectiva da empresa em relação aos prováveis resultados positivos derivados da exploração das grandes jazidas de petróleo em profundidades marinhas, levou a companhia a investir 1\% do seu faturamento em P\&D, tornando-se um dos maiores programas tecnológicos da história do país (Bruni, 2002). Este dispêndio tem sido compensador para a Petrobras, pois segundo Carlos Tadeu da Costa Fraga, gerente-executivo do Cenpes, o retorno do investimento foi de US\$ 4,3 para cada dólar gasto no início do Procap, e que em 2004, o retorno já havia aumentado para US\$ 8,2 (desafio, 2005).

Grande parte destes recursos são investidos no Cenpes - Centro de Pesquisas e Desenvolvimento Leopoldo A. Miguez de Mello, da Petrobras - criado dez anos após a fundação da Petrobras (1953), atualmente em funcionamento na Universidade Federal do Rio de Janeiro, na Ilha do Fundão. 0 primeiro grande feito do Cenpes ocorreu em 1968, quando a partir de suas pesquisas, encontraram a primeira bacia petrolífera no mar brasileiro, no Campo de Guaricema (SE) (Centro, 2005). Entretanto, a empresa condizente com os preceitos positivos da pesquisa em grupo, envolverá o Procap numa rede de pesquisa com concorrentes, fornecedores e instituições de pesquisa. A primeira, e talvez principal, aliada é o Instituto Alberto Luiz Coimbra de Pós-Graduação e Pesquisa de Engenharia da UFRJ, o Coppe, onde já atingiram o marco de 1.000 projetos concluídos em parceria com a Petrobras, e que originou, em 1994, o Grupo Interdisciplinar em Tecnologia Submarina, atuando nos mais diversos programas: robótica, soldagem, hidro-acústica, etc. (Pesquisa, 2005). Outro grande aliado da Petrobras na pesquisa em tecnologia offshore é o Centro de Estudos em Petróleo (Cepetro), da Faculdade de Engenharia Mecânica da Unicamp, criado em 1987 com o apoio da Petrobras. O Centro além de ser parceiro em pesquisa, contribui de forma significante na formação de mão-de-obra qualificada (Cepetro, 2005). São várias as outras instituições, como a Poli-USP e Instituto de Pesquisas Tecnológicas de São Paulo, que irão se mostrar fundamentais para a manutenção do Procap ${ }^{3}$ durante os anos.

Foi através desta conjunção de instituições, que a pesquisa e os resultados da Petrobras avançaram na tecnologia offshore. Sendo que a evolução foi formada pelo desenvolvimento de rotinas e de maneira gradual, conforme as seções posteriores demonstram.

\subsubsection{Procap 1: O início da exploração no segmento Offshore entre 1986-1991}

Esse programa foi executado durante 6 anos e empreendeu 109 projetos, visando melhorar a competência técnica da empresa na produção de petróleo e gás natural em águas com profundidade de até 1000 metros (Bruni, 2002). Durante os seis anos do programa, 80\% dos projetos, foram voltados para extensão da tecnologia já existente e $20 \%$ para inovação tecnológica (Pesquisa, 2005).

\footnotetext{
${ }^{3}$ Ainda em relação à disponibilização de recursos para P\&D, a empresa recebe investimentos através do CTPETRO, o primeiro fundo setorial para desenvolvimento científico e tecnológico, criado em 1998, pelo Plano Nacional de Desenvolvimento Científico e Tecnológico, na tentativa do governo federal em promover um sistema nacional de inovações. O fundo é abastecido basicamente pelos royalties do petróleo e está sob a responsabilidade conjunta da Agência Nacional do Petróleo - ANP e do Ministério de Ciência e Tecnologia. É dirigido por um fundo gestor, operado pela FINEP, com participação de acadêmicos e empresários.
} 
Inovações do Procap 1 A consagração do primeiro Procap foi a instalação do sistema de produção flutuante e antecipada na bacia de Marlim, em 1.027 metros de lâmina d'água, no qual o desempenho da plataforma flutuante, iria coroar o futuro deste sistema, por ser acompanhado, além da viabilidade técnica, de uma maior rentabilidade econômica do que os outros modelos. Em síntese, este novo modelo, apresentou uma série de vantagens sobre os demais, como: um menor tempo de instalação; a possibilidade de servirem como unidades provisórias de produção, pois por não ter estrutura fixa, a plataforma poderá ser removida para novos espaços. O sistema de produção de Marlim I, que envolveu a construção de uma nova plataforma, teve um custo total de US\$ 1,331 bilhão para uma produção de 100.000 bpd $^{4}$ de petróleo. Já o sistema TLP de Auger ${ }^{5}$, teve um custo bastante próximo: US\$ 1,2 bilhão, mas para uma produção bastante inferior: 46.000 bpd de petróleo. As grandes companhias operadoras têm reconhecido que os sistemas de produção flutuante (SPF) apresentam melhores custos e mais opções para o desenvolvimento de campos produtores em águas profundas (Furtado, 1996).

Com seu conhecimento consolidado, a empresa redirecionou seus objetivos, ao pensar que as inovações deveriam deixar de serem incrementais para serem absolutas. Tal decisão foi tomada porque a tecnologia disponível já não era mais condizente com as profundidades que a estatal brasileira almejava explorar.

\subsubsection{Procap 2000: Aprendizado e desenvolvimento da pesquisa interna na Petrobras entre 1993 - 1999}

O sucesso do Procap encorajou a empresa a criar em 1993 o PROCAP-2000, estendendo a pesquisa para a exploração nos 2.000 metros de profundidade. Este programa desenvolveu 20 projetos, com orçamento de cerca de US\$ 750 milhões. Além da expansão dos limites da exploração, o programa visava também, a redução de custos de produção. Para isso $80 \%$ dos projetos foram voltados para inovações e $20 \%$ para extensão, exatamente o contrário da fase anterior (Furtado e Freitas, 2004).

Um grande desafio que ocorreu durante este programa, foi a descoberta de mais uma jazida em 1996, que se tornaria uma das maiores preciosidades da Petrobras, por tratar-se de um campo gigante de Petróleo (132 $\mathrm{Km}^{2}$ ), o campo de Roncador, na Bacia de Campos (RJ), a 1.853 metros de profundidade, com lâmina d'água entre 1.500 e 2.000 metros, reservas de 3,3 bilhões de boe ${ }^{6}$, espessura de reservatório de até 200 metros e óleo entre 180 e 311 API $^{7}$, considerado leve. Além das reservas, muita da tecnologia desenvolvida para este campo foi utilizada em outros campos, como declarou José Fomigli, gerente da Plataforma Marlim: "Roncador representou um degrau fundamental para o desenvolvimento de outras unidades" (Petrobras, 2005).

A descoberta chegou quando a empresa não possuía equipamentos suficientes para a produção. Mas com o objetivo de garantir o controle sob a reserva, uma vez que o mercado já mostrava fortes tendências para a abertura, o que ocorreu em 1997, a direção da Petrobras, então, por não possuir tempo hábil para construir uma nova plataforma, teve de optar pela readaptação de uma plataforma já existente, a Plataforma 36 (P-36), que operava no campo de Marlim (comprovando o ganho no potencial de exploração do SPF frente ao TLP). Campo este que possui uma profundidade menor (1.360 metros), qualidade diferente do mineral (mais pesado) e quantidade inferior, o que criou a necessidade de readaptar todo o sistema, como o mecanismo de injeção de água dentro do reservatório. O sucesso no empreendimento, trouxe para a empresa nacional, o título de referência e liderança tecnológica para o mundo do petróleo

\footnotetext{
${ }^{4} \mathrm{Bpd}=\mathrm{Bbl}$, que significa barris por dia (1 barril equivale a 158,98 litros ou $0,159 \mathrm{~m} 3$ ).

${ }^{5}$ Plataforma da Shell Oil

${ }^{6}$ Barris de Óleo Equivalente - usado para expressar volumes de petróleo e gás natural em barris, através da conversão de $1 \mathrm{~m}^{3}$ de gás ou petróleo em 6,289941 barris de petróleo.

${ }^{7}$ American Petroleum Institute - é a forma de expressar a densidade relativa de um óleo ou derivado. Sendo que quanto menos denso for o petróleo, mais leve ele será, significando uma qualidade superior. A escala API, medida em graus, varia inversamente à densidade do petróleo, ou seja, o petróleo mais leve (menos denso) será o de maior grau. Segundo esta escala, quando a escala for de 0-10, o petróleo será extrapesado; entre 11-22, petróleo pesado; 22-30, médio; e maior que 30, leve.
} 
offshore, confirmado em 2005, com o recebimento no mês de março, do "Distinguished Achievement Award - OTC'2001" (Pesquisa, 2005).

A descoberta do campo de Roncador, na bacia de Campos (RJ), e outras que aconteceram, levou o "petróleo marinho" a representar no ano de $2000,75 \%$ das reservas de petróleo e gás no Brasil. Estes produtos continuaram sendo explorados unicamente pela Petrobras, que obteve um aumento proporcional na produção. Em 1987, apenas 1,7\% da produção era marinha, já em 2000, o porcentual passou para 55\% (Bruni, 2002).

A busca pela viabilidade econômica na produção em profundidades cada vez maiores, tornou-se um desafio para a Petrobras, que sofreu uma reestruturação de mercado em 1997, com a criação da Agência Nacional de Petróleo - ANP - e respectiva abertura do mercado às firmas estrangeiras.

Inovações do Procap 2 - Inovações para explorar o petróleo de Roncador Como estratégia para reconhecimento rápido e seguro do campo, a Petrobras utilizou um sistema antecipado de produção com o navio Seillean, um FPSO-DP ${ }^{8}$, alugado da Reding\&Bates que, através de adaptações para o novo poço, tornou-se o primeiro navio de posicionamento dinâmico do mundo a operar nessas profundidades, utilizando um conjunto de propulsores que mantém seu posicionamento a partir da orientação dada por sensores instalados no fundo do mar e pelo sistema de GPS ${ }^{9}$. A utilização do navio foi temporária até a adaptação da plataforma P-36.

Em relação aos propulsores, a tecnologia empregada foi considerada como o limite tecnológico do período. Para o funcionamento destes propulsores, foi utilizada uma tecnologia submarina inédita, com destaque para um sistema subsea composto por um drillpipe riser $^{10}$ e uma árvore de natal molhada TLD 2000. O drillpipe riser é um sistema novo de riser de composição que pode ser montado de forma mais ágil e segura, além de usar um tipo de rosca que permite descer a profundidades cada vez maiores. O riser fica instalado em cima da árvore de natal recolhendo a sua produção.

Para a chegada da plataforma 36, foram desenvolvidas novas tecnologias em parceria com outras instituições, entre elas uma nova árvore de natal molhada horizontal, a ANMH-2500 ${ }^{11}$. Um dos destaques da nova árvore é a desconexão rápida, que torna o projeto mais seguro, uma vez que todo o sistema antecipado está baseado no posicionamento dinâmico. Ela é horizontal pois a perfuração agora poderá ser não apenas na vertical, o que amplia a dinâmica da perfuração.

Outra inovação foi no sistema de ancoragem da plataforma, nome dado ao conjunto: árvore de natal, drillpiper e riser. Isto porque o conjunto determina o local onde a plataforma se encontra. A inovação foi especificamente no riser, que passou a ser constituído de poliéster. O projeto deste novo material, foi desenvolvido no Laboratório da Petrobrás (Cenpes) e executado pelas empresas Quintas e Quintas, de Portugal, e pela Cordoaria São Leopoldo, do Rio Grande do Sul. Este sistema de ancoragem foi inventado para o campo de Marlim e é um tipo de ancoragem mais eficiente e com menor custo. A vantagem do poliéster é o fato de ser mais leve e mais resistente à tração, o que demandará menos energia no transporte do óleo, que perde menos vazão, aumentando assim a produção e a receita do campo. Além disso, o custo de instalação é reduzido em quase $20 \%$ (Petrobras, 2005).

Um destaque importante no projeto Roncador foi o sistema de geração elétrica da P-36 e da P-47, ambas próximas, gerada por turbinas a diesel instaladas na P-36, a energia é transmitida para a P-47 através de cabos instalados no fundo do mar, podendo ser usado em até 2.000 metros de profundidade. A distância entre as duas unidades é de cerca de mil metros.

Além das inovações para a exploração do campo de Roncador, foram desenvolvidas outras tecnologias durante o Procap 2000:

\footnotetext{
${ }^{8}$ Floating Production Storage and Offloading Systems - Sistemas Flutuantes de Produção e Armazenamento, a transformação de um navio superpetroleiro em plataforma de produção de petróleo (Fraga, 2002).

${ }^{9}$ Instrumento tecnológico que permite a exata localização geográfica via satélite.

${ }^{10}$ No qual o drillpipe é um sistema de perfuração e o riser são os "dutos" por onde o petróleo é levado até a superfície.

${ }^{11}$ Fabricada em conjunto com a ABB, FMCICBV, Cooper Cameron e Kvaerner, e feito um upgrade em uma árvore da Drill-Quip.
} 
- O SGN, Sistema Gerador de Nitrogênio, é um sistema que funciona como um gerador de calor para retirar a parafina que se forma nas paredes dos risers.

Estas tecnologias, foram desenvolvidas conforme a necessidade atual da Petrobras. Mas além disto, a empresa, antecipando as necessidades futuras, e para aproveitar o conhecimento disponível do momento, desenvolveu tecnologias para poços ainda não descobertos, que demandariam por tecnologia de profundidade ainda maior. Nesta concepção foi realizado o poço de longo alcance, que permite a drenagem de várias locações do reservatório a partir de uma mesma origem. A nova tecnologia mostrou-se necessária alguns anos depois, no início de 2005, com a perfuração de um poço em Marlim Sul, em lâmina d'água de 1.500 metros e com 4,4 mil metros de afastamento horizontal. Neste caso, se fosse apenas um ponto de origem, o volume de produção seria muito inferior.

Quando os limites de 2.000 metros foram alcançados, a direção da Petrobras, ampliou as metas, criando um novo Procap.

\subsubsection{Procap 3000: Estágio atual e perspectivas de pesquisa da Petrobras entre 2000-2006}

O Procap 3000 terá a duração de seis anos e orçamento inicial de US\$ 128 milhões em P\&D, no qual estão sendo mobilizados 350 funcionários. A previsão é que sejam executados 19 projetos. As metas do programa são: viabilizar a produção de Marlim Leste e Albacora Leste, na bacia de Campos (RJ), e das próximas fases de Roncador e Marlim Sul; possibilitar a produção a três mil metros de profundidade; reduzir os investimentos no desenvolvimento da produção em lâmina d'água superior a mil metros e contribuir para a redução dos custos de extração dos campos em produção (Petrobras, 2005).

\section{Inovações no Procap 3}

- os risers para três mil metros. Entre as alternativas estudadas está o uso do riser híbrido, utilizando metal e materiais compostos como a fibra de carbono ou outros compostos plásticos.

- A equipe do Procap 3000 estuda também o desenvolvimento de uma nova árvore de natal totalmente elétrica, que não utilizaria os atuais atuadores hidráulicos. Segundo Marcus Coelho, um dos responsáveis pelo Procap, destacou que "a tecnologia de perfuração a esta profundidade já existe. Em dezembro de 1999, perfuramos um poço exploratório a 2977 metros. O Procap 3000 está voltado para o desenvolvimento da produção" (Petrobras, 2005).

- O Cenpes, junto com o IPT - Instituto de Pesquisas Tecnológicas de São Paulo - desenvolveu um programa laboratorial que serve para simular as deformações das rochas ao longo do tempo, muito comum nas rochas de sal, e que podem levar a destruição completa de todo o sistema de prospecção do petróleo. Tal aparato permitirá a exploração de um poço recém descoberto, na Bacia de Santos (SP), que tem início nos 2.000 metros, mas que tem uma grande camada de sal, até chegar ao fundo do poço, em 6.407 metros (Exploração, 2005). Além disto, o aparato representa uma nova era na exploração offshore, pois estas deformações têm sido um dos principais entraves para a prospecção de petróleo em muitas regiões do planeta.

- O Cenpes, conjuntamente com a SGI, empresa americana de supercomputadores, numa empreitada semelhante a inovação acima, estão desenvolvendo uma sísmica 4D, que permite a visualização das imagens em 3 dimensões, mais a quarta, que é o tempo. Assim, será possível determinar o ponto exato, bem como o fluxo do petróleo, em qualquer profundidade, que ampliará as reservas do Brasil e do mundo (desafio, 2005).

No intuito de minimizar perdas, que podem chegar à viabilização da exploração de poços de petróleo, a Petrobras criou o Programa de Recuperação Avançada de Petróleo - PROVAP-, que tem como objetivo: Viabilizar a produção de campos considerados subcomerciais por limitações tecnológicas; Produzir 
técnicas e padrões de gerenciamento de reservatórios que permitam elevar, com vantagem econômica, o fator de recuperação de campos de petróleo; Contribuir para a revitalização de campos maduros, sem negligenciar a preservação do meio ambiente (PROVAP, 2005).

\section{CONSIDERAÇÕES FINAIS SOB O RESPALDO TEÓRICO}

Serão agora apresentadas as principais atividades desenvolvidas pela Petrobrás, no que tange ao processo de inovações tecnológicas, e que podem ser visualizadas num contexto teórico, demonstrando assim, que ao menos no caso desta empresa, os princípios teóricos dos evolucionários, surtiram em resultados bastante positivos.

\subsection{Característica da cumulatividade do conhecimento}

Esta é uma premissa não exclusiva dos autores evolucionários, mas que está intrinsecamente ligada aos diversos princípios destes.

As primeiras descobertas das jazidas de petróleo submersas, mostraram apenas o potencial da produção, no entanto, o conhecimento tecnológico impedia a efetivação das descobertas. Para solucionar tal problema, e com o conhecimento brasileiro em exploração offshore quase nulo, os decision makers resolveram adquirir tecnologia no exterior e contribuir apenas com pequenos aperfeiçoamentos, até que $o$ acúmulo fosse suficiente para desenvolver tecnologia própria.

Após este "passo inicial", a cumulatividade no conhecimento num ritmo monotonicamente crescente, permitiu que os limites de profundidade de 1.000, 2.000 e 3.000 metros fossem rompidos sucessivamente. A formação do conhecimento não possibilitava que fossem exploradas jazidas de 3.000 metros, sem antes passar pelos 2.000 metros. E agora, com tecnologia suficiente, os dirigentes da empresa já prevêem a possibilidade técnica de exploração aos 4.000 metros.

Além das profundidades, vários foram os mecanismos tecnológicos necessários para a exploração do petróleo desenvolvidos pela empresa, mas ainda falta um importante sistema, que são as plataformas. Até o presente momento o Brasil não possui tecnologia para a produção destas, mas isto está próximo de acabar, pois o atual acordo de transferência tecnológica com Singapura, para a produção de duas plataformas, prevê o arranjo entre a Petrobras e os estaleiros nacionais, para que as plataformas sejam produzidas localmente, ainda com tecnologia asiática. Com a absorção do conhecimento, no futuro o país terá condições de produzir isoladamente as plataformas, ou ao menos, boa parte das mesmas.

Mas no geral, devido os diversos objetivos alcançados pela pesquisa referente à Petrobras, formando todo um estoque de conhecimento que outros países não possuem, o que criou um gap tecnológico em relação aos demais, gerando um caráter de liderança à companhia brasileira de petróleo.

\subsection{Trajetórias}

Como descrito no primeiro capítulo, as trajetórias variam de tal maneira que uma pode substituir a outra. Um exemplo disto, foi a modificação na estrutura das plataformas. Os primeiros países utilizavam unicamente a sustentação fixa, mas frente às deseconomias de escala decorrentes do aumento da profundidade, os estudos (trajetórias) avançaram para uma outra técnica, a sustentação flutuante. Esta trajetória viabilizou o paradigma offshore para profundidades maiores do que 500 metros.

A tecnologia das sondas, também demonstra o mesmo perfil. Se antes as sondas eram acopladas nos barcos, para ganhar maior eficiência, estas sondas transformaram-se em barcos, e alguns destes, em plataformas de produção de menor escala. 


\subsection{Alianças empresariais em projetos de P\&D}

A simetria com o postulado teórico em questão, ocorre já no período inicial do programa de exploração de petróleo offshore, quando a Petrobras formou uma aliança vertical com os estaleiros nacionais para a produção local dos barcos sonda. Logo após, a Petrobras criou parceria nos programas de P\&D com as instituições de pesquisa tecnológica da Unicamp (Cepetro) e da UFRJ (Coppe). Além destas instituições, muitas empresas privadas desenvolveram tecnologia conjuntamente com a Petrobras, em geral fornecedores, dentre os quais pode-se destacar: Cordoaria São Leopoldo, na criação do riser de poliéster; a americana SGI, do ramo de supercomputadores,; estaleiro nacional e internacional para o desenvolvimento de plataformas nacionais.

\subsection{Oportunidade de novos negócios}

Uma outra importante atribuição decorrente dos investimentos em inovação tecnológica, está no grande potencial em se criar novas oportunidades de negócios. Estas externalidades, mesmo num ramo tão específico da ciência, quanto à tecnologia offshore, não se mostraram uma exceção.

Neste contexto, segundo Furtado e Freitas (2004), esta foi uma das principais conseqüências do primeiro Procap. Na realidade, o que aconteceu, é que das diversas inovações tecnológicas surgidas neste período, muitas puderam ser empregadas em outras atividades marítimas, como o sistema de amarração de toda a estrutura flutuante das plataformas, que passaram a ser utilizadas também em embarcações, principalmente as submarítimas, pois permite uma maior segurança frente a pressão atmosférica de grandes profundidades. Os robôs submarinos foram outra inovação, ao substituir os mergulhadores no serviço de interligar a plataforma com os poços submarinos que se tornaram referência para a produção de robôs para operar em grandes profundidades. O desenvolvimento dos estaleiros nacionais, em sua maioria instalados no Rio de Janeiro, estão contribuindo em muito para a geração de empregos no Estado, diante da demanda da Petrobrás por embarcações e navi-peças, sendo, portanto, mais uma externalidade da tecnologia offshore.

Nos três Procaps houve também, um importante impacto nos recursos humanos das instituições envolvidas com a pesquisa da Petrobras, principalmente nos cursos de engenharia da Unicamp e UFRJ. Este efeito spin off do conhecimento, proporcionou não exatamente numa oportunidade de negócios, mas ainda assim uma externalidade positiva para a sociedade.

\subsection{Investimento em tecnologia como fator de convergência entre os países}

E por fim, em relação à convergência para com os países em desenvolvimento, que os avanços tecnológicos tendem a oferecer, como uma das premissas dos "evolucionários", pode ser incorporada às conseqüências positivas resultantes da dedicação da Petrobras. Isto pode ser concebido pela proximidade da auto-suficiência em petróleo no Brasil, devido à prospecção de petróleo em águas profundas, como mostra a produção de 2004 de 540.717 .037 barris, aproximadamente $85 \%$ provém de zonas marítimas (462.084.935 barris) (Produção, 2005). A convergência de renda surge, ao considerar a melhoria no bem estar da população, pelo fato do país estar menos vulnerável aos eventuais choques na oferta do insumo, e conseqüentemente, uma pressão inflacionária menor, melhorando o cenário macroeconômico do país. Outra variante, está na possibilidade de poupar divisas, que seriam destinadas à importação do petróleo.

Outra conseqüência importante, e que pode servir indiretamente como exemplo de convergência, está no fato do desempenho da Petrobras ter criado uma das principais experiências brasileiras na constituição de um sistema nacional de inovações, dado que a industrialização brasileira é dominada pela presença de multinacionais e sem muitos exemplos de tecnológicas originais. E a presença de um sistema nacional de inovações, acreditando em todo o potencial dinâmico positivo em torno do progresso técnico, será mais condizente com a pretensão do país tornar-se um país industrializado. 


\section{Referências Bibliográficas}

Bell, M., Ross-Larson, B., \& Westphal, L. E. (1984). Assessing the performance of infant industries. Journal of Development Economics, 16(1-2):101-128. available at http: //ideas . repec .org/a/eee/ deveco/v16y1984i1-2p101-128.html.

Bruni, P. B. (2002). Petrobras: Estratégia e esforço tecnológico para alavancar competitividade", análise da conjuntura das indústrias do petróleo e do gás. disponível em: http://www.ie.ufrj.br/infopetro/pdfs/petrogas-mar2002.pdf.

Centro (2005). Centro de pesquisa da petrobras: Linha do tempo. disponível em: http://www2.petrobras.com.br/tecnologia2/port/centro_pesquisasdapetrobraslinhatempo.asp. Acesso em 10 outubro 2005.

Cepetro (2005). Cepetro: Centro de estudos em petróleo. disponível em: http: //www . cepetro . unicamp.br/. Acesso em 13 maio 2005.

Debeir, J.-C. e. a. (1993). A Expansão do Sistema energético capitalista, Uma história da energia. Ed. da UnB, Brasília. p. 169-206.

desafio, O. (2005). O desafio dos óleos pesados. disponível em: http://www . dep.fem.unicamp.br/ boletim/BE38/artigo.htm. Acesso em 10 outubro 2005.

Dosi, G. (1982). Technological paradigms and technological trajectories : A suggested interpretation of the determinants and directions of technical change. Research Policy, 11(3):147-162. available at http://ideas.repec.org/a/eee/respol/v11y1982i3p147-162.html.

Dosi, G. (1988). Technical Change and Economic Theory, chapter The nature of the innovative process, pages 221-238. Pinter Publisher, Londres \& Nova York.

Exploração (2005). Exploração: Petrobrás confirma vestígios de petróleo na bacia de campos. jornal Gazeta do Povo. p.24.

Fraga, O. (2002). A parceria empresa-universidade em alto-mar: o caso das plataformas da petrobras. $R e$ vista Politécnica On Line, (246). disponível em: http://www . poli .usp.br/RevistaPolitecnica/ busca . asp?results=results.

Frankel, M. (1955). Obsolescence and technological change in a maturing economy. American Economic Review.

Freeman, C. \& Soete, L. (1997). The economics of industrial innovation, volume 3. MIT press edition, 3 edition. p.85-105; 265-285.

Furtado, A. T. (1996). La trayectoria tecnológica de petrobrás en la producción costa afuera. Revista Espacios, 17. http://www. revistaespacios.com/a96v17n03/32961703.html.

Furtado, A. T. \& Freitas, A. G. (2004). Nacionalismo e aprendizagem no programa de Águas profundas da petrobras. Revista Brasileira de Inovação, 3(1):55-86.

História (2005). História do petróleo no brasil. disponível em: http://www.comciencia.br/ reportagens/petroleo/pet06.shtml.

Pesquisa (2005). Pesquisa petrolífera do brasil na fronteira do conhecimento. disponível em: http: //www.comciencia.br/reportagens/petroleo/pet07.shtml. 
Petrobras (2005). Petrobras na vanguarda. disponível em: http://www.dep.fem.unicamp.br/ boletim/be10/Artigo\_Petrobrasnavanguarda\%.htm.

Produção (2005). Produção nacional de petróleo. disponível em: http://www.anp.gov.br/doc/ dados\_estatisticos/A48.

PROVAP (2005). Provap. disponível em: http://www2.petrobras.com.br/tecnologia/ portugues/programas\_tecnologic\%os/pravap.stm.

Rosenberg, N. (1969). The direction of technological change: Inducement mechanisms and focusing devices. Economic Development and Cultural Change, 18(1):1-24. available at http://ideas.repec.org/a/ucp/ecdecc/v18y1969i1p1-24.html.

Rosenberg, N. (1982). Inside the black box. Press of University of Cambridge. p. 81-140.

Teece, D. (1988). Technological change and the nature of the firm. Pinter Publisher, Londres \& Nova York. p.256-281. 